\title{
Early Surgical Results of Patients With Pertrochanteric Fractures Treated With Proximal Femoral Locked Plates
}

\section{Proksimal Femoral Kilitli Kompresyon Plağı ile Tedavi Edilen Femur Pertrokanterik Kırıklı Hastaların Erken Dönem Sonuçları}

\author{
Sezgin Semis, İsmail Burak Atalay, Selçuk Yılmaz, Murat Arıkan, Emre Özanlağan \\ Sağlık Bakanlığı Ankara Onkoloji Eğitim Ve Araştırma Hastanesi, Ortopedi Ve Travmatoloji Kliniği
}

Dergiye Ulaşma Tarihi: 23.10.2015 Dergiye Kabul Tarihi: 02.11.2015 Doi: 10.5505/aot.2015.21939

\section{ÖZET}

Giriş ve Amaç: Bu çalışmamızda amacımız; proksimal femoral kilitli kompresyon plağı ile tedavi ettiğimiz, pertrokanterik kırığı olan 48 hastanın, erken dönem radyografik ve klinik sonuçları ile tedavi yönteminin stabil olmayan kırıklarda da avantajlarını ortaya koymaktır.

Yöntem ve Gereçler: Hastaların 28'i kadın, 20'si erkek idi. Hastaların 8 inde subtorkanterik kırık, 40 hastada intertrokanterik kırık mevcuttu. Hastalarımızın hastaneye başvuru anından sonra ameliyat olma süreleri ortalama 2,2 gün olarak belirlendi. Hastaların tamamına proksimal femoral kilitli kompresyon plağı ile stabilizasyon yapild1.

Bulgular: Hastaların ortalama takip süresi 11,8 ay olarak belirlendi. 48 hastanın 1'inde derin ve 2'sinde yüzeyel olmak üzere 3 (\%6) hastada enfeksiyon gelişti. 48 hastanın 43’ünde (\%89) kaynama sağlandı.

Tartışma ve Sonuç: Çalışmamızda, pertrokanterik femur kırıklarının tedavisinde proksimal femoral kilitli kompresyon plağının kullanılması ile post operatif morbiditenin daha düşük, kaynama süresinin ise daha kısa olduğunu bulduk.

Anahtar Kelimeler: Pertrokanterik kırık, Proksimal femur kilitli plak

\section{ABSTRACT}

Introduction: The aim of this study is to analyze the early radiologic and clinical results of 48 patients with pertrochanteric fractures treated with proximal femoral locked plates and the advantage of this treatment method in non stable fracture patterns

Methods: 28 female and 20 male patients were analyzed. Subtrochanteric fractures in 8 and intertrochanteric fractures in 40 patients were recorded. The mean period for operation after admission to hospital is 2.2 days. Proximal femoral locked plate was used for reconstruction in all patients.

Results: Patients were followed up for a mean period of 11.8 months. 1 deep and 2 superficial infections were recorded. Bony union was examined in 43 of 48 patients $(89 \%)$.

Discussion and Conclusion: In this study, we analyzed that, proximal femoral locked plate is a good surgical option for pertrochanteric fractures as it provides low morbidity rates and shorter union time.

Key words: Pertrochanteric fracture, Proximal femoral locked plate

\section{Giriş}

Pertrokanterik kırıkların \%95'i yaşlılarda düşük ve orta enerjili travmalarla diğer $\% 5$ 'i genç nüfusta yüksek enerjili travmalarla meydana gelir (1). Yaşam süresinin artmasına paralel olarak özellikle instabil trokanterik parçalı kırık tiplerinin sıklığı artmaktadır $(2,3)$. $\mathrm{Bu}$ hasta grubunda uygulanacak tedavi yöntemleri, en kısa sürede hastanın ayağa kaldırılmasına ve hareketliliğine izin veren, yeterli redüksiyon ve sağlam bir tespit sağlayan, böylece hastanın kırık öncesi duruma dönmesini sağlayarak önemli komplikasyonların önüne geçilmesini hedef almalıdir (4).
Hastaların yatağa bağımlılıktan kurtarılıp daha erken mobilize edilmeleri ve kırık öncesi yaşam standartlarına daha erken dönebilmeleri, cerrahi tedavi metodları ile mümkün olmaktadır. Tedavide kırığa uygun implant seçimi de oldukça önemlidir. $(1,5)$.

$\mathrm{Bu}$ çalışmamızda amacımız; proksimal femoral kilitli kompresyon plağı ile tedavi ettiğimiz, pertrokanterik kırı̆̆ı olan hastaların, erken dönem radyografik ve klinik sonuçları ile tedavi yönteminin stabil olmayan kırıklarda da avantajlarını ortaya koymaktır. 


\section{Gereç ve Yöntem}

2012-2014 yılları arasında Sağlık Bakanlığ 1 Dr. Abdurrahman Yurtaslan Onkoloji Eğitim ve Araştırma Hastanesi Ortopedi ve Travmatoloji Kliniği'ne başvuran 48 pertrokanterik kırığı olan hastaya açık ve/veya kapalı redüksiyon ve Proksimal Femoral Kilitli Kompresyon Plağı ile fiksasyon ameliyatı yapıldı.

Hastaların 28 i erkek (\%58), 20 si kadındı (\%42). Hastaların yaş ortalaması 57,2 idi (Yaş aralığı 23-90). Hastaların 8 (\%17) inde subtrkanterik kırık, 40 (\%83) hastada intertrokanterik kırı mevcuttu (Tablo 1). Hastalardan alınan öyküye göre, kırıkların oluş nedenleri 9 olguda yüksekten düşme, 7 olguda trafik kazası, 32 olguda evde düşme sonucudur (Tablo 2). Pertrokanterik kırık nedeniyle tedavi edilen hastaların 5 tanesinde eşlik eden başka kırıklar mevcuttu.

Tablo 1: Hastaların kırık tipine göre dağılımı

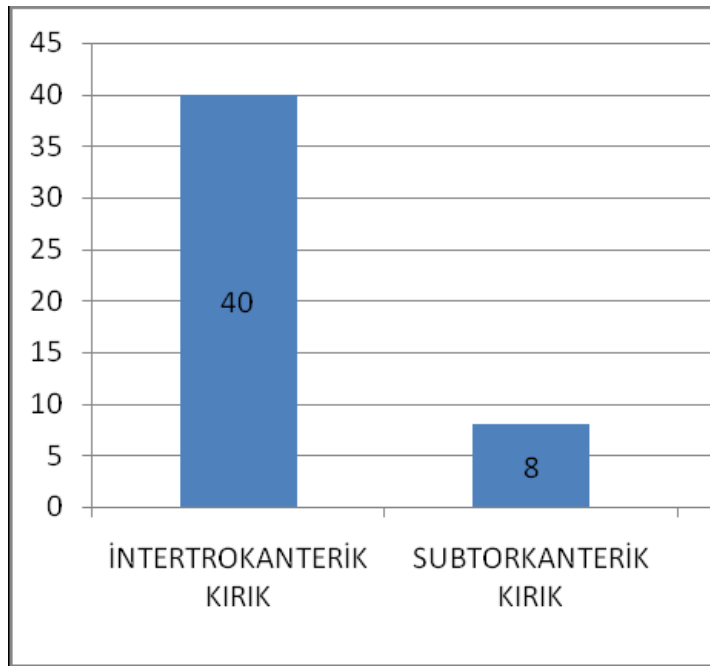

Hastalar klinik olarak değerlendirildikten sonra radyolojik tetkiklere geçildi. Tüm hastalara standart pelvis ön-arka grafisi ve etkilenen kalçanın ön-arka ve yan grafileri çekildi. Kalça önarka grafisi çekilirken uyluk 15 derece iç rotasyona alınarak anteversiyon düzeltildi ve proksimal femurun gerçek ön-arka grafisi çekilmiş oldu. Hiçbir hastada bilgisayarlı tomografi çekim ihtiyacı olmadı. Kırık tespit edilen hastalara $2 \mathrm{~kg}$ cilt traksiyonu tatbik edildi. Dahili yönden gerekli testler ve anestezi konsültasyonları yapild.

Tablo 2: Kırık oluş nedenleri

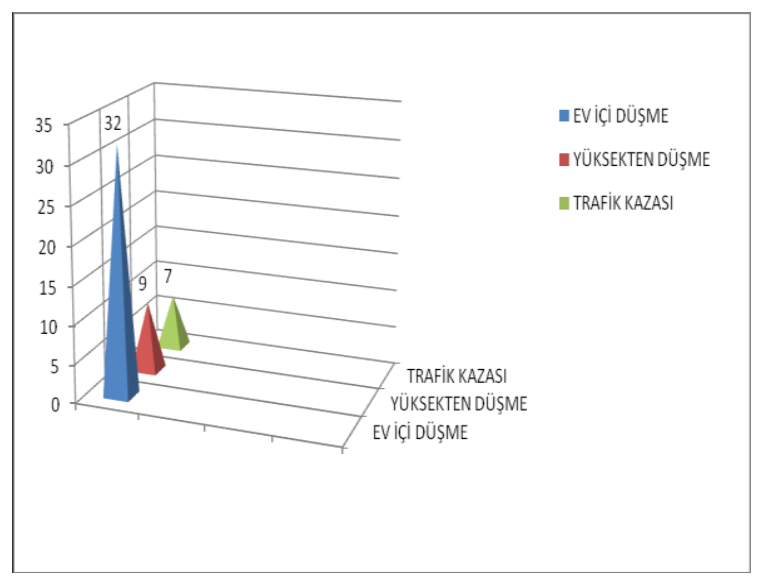

Subtrokanterik kırığı olan hastalarda Seinsheimer sinıflaması, intertrokanterik kırığ1 olan hastalarda Boyd-Grifin sinıflamas1 kullanıldı. İntertrokanterik kırı̆ğ olan 40 hastanın 14'ü tip 1 (35), 8'i tip 2 (\%20), 13 ü tip 3 (32), 5 i tip 4 (\%13) olarak sınıflandırıldı . Subtrokanterik kırığ 1 olan 8 hastanın; 3 ü tip 2 (\%37), 3 ü tip 3 $(\% 37), 2$ si tip $4(\% 25)$ olarak sinıflandirıldı.

Bütün hastalara operasyondan 30 dk önce 1.kuşak sefalosporin grubundan 1 gr IV antibiyotik uygulandı ve ameliyat sonrası 3 gün devam edildi.

Tüm hastalara hastaneye yattığ andan itibaren antitromboembolik tedavi olarak düşük molekül ağırlıklı heparin başland1 ve ameliyat sonrası 20.güne kadar devam edildi. Hastaların tamamına yüksek uyluk antitromboembolik çorap ameliyat sonras1 6.haftaya kadar uyguland1.

Hastaların hiçbirinde açık kırık saptanmadı ve hiçbir hastada damar sinir yaralanması görülmedi. Hastaların ortalama hastaneye başvuru süresi 1.3 gündü (1-4 gün). Geç başvuruların sebebi bazı hastaların dış merkezdeki başka bir hastaneden kliniğe sevk edilmeleri ve bazı 
hastaların dahili problemlerine yönelik uygun tedavi süreleri tamamlamalarıyd. Hastaların hastaneye başvuru anından ameliyat olma süreleri ortalama 2.2 olarak belirlendi.

Hastalar ameliyat masasına supin pozisyonda yatırıldı. Hiçbir vakada traksiyon masası kullanılmadı. Redüksiyon için sırasıyla abdüksiyon, diş rotasyon, addüksiyon ve iç rotasyon manevraları yapıld1. Trokanter majörün $2 \mathrm{~cm}$ proksimalinden başlayan distale doğru uzanan ortalama $12 \mathrm{~cm}$ insizyon yapıld. Minimal invaziv plak osteosentezi (MIPO) yapılan 6 hastada insizyon uzunluğu $5 \mathrm{~cm}$ idi. Vastus lateralis proksimal muskulotendinöz bileşkeden L flep olarak kaldırıldı. Kırık redüksiyonu sonrası uygun plak ve proksimale en az 3 adet $6.5 \mathrm{~mm}$ kanüllü kilitli vida, distale uygun sayıda $4.5 \mathrm{~mm}$ kortikal kilitli vida ile stabilizasyon sağlandi.

MIPO yapilan 6 hastada redüksiyonu takiben trokanter majorun tepesinden başlayan $5 \mathrm{~cm}$ insizyon yapıldıktan sonra plak trokanter majör üzerinden distale doğru kaydırıldı. Proksimal vidaların tespitinden sonra eksternal guide yardımıyla distal vidalar yerleştirildi.

Hastalar standart olarak ameliyat sonras1 1. günde fizyoterapist eşliğinde yatak başında oturtulduktan sonra yürüteç veya koltuk değneği yardımıyla yük vermeden mobilize edildi. Diz ve kalça ROM egzersizleri operasyon sonrasi 1. günde kademeli olarak başlandı

Bütün hastaların rutin olarak operasyon sonrası 6 . hafta kontrolünden sonra kontrollü olarak yük vermesine izin verildi. Hastalar klinik ve radyolojik olarak post-op 6. Hafta, 3. Ay, 6. Ay ve 12. Ay'da kontrole çağırılarak takip edildi.

\section{Bulgular}

Hastaların ameliyat öncesi risk değerlendirmesi ASA kriterlerine göre Anestezi Kliniği tarafından değerlendirilmiştir. Ameliyat ettiğimiz 48 hastanın 9'u ASA 1 (\%18), 19'u ASA 2 (\%39), 10'u ASA $3(\% 20)$ ve 10 hasta ASA $4(\% 20)$ olarak bulunmuştur. (Tablo 3)

Pertrokanterik kırık nedeni ile proksimal femoral anatomik plak tespiti yapılan olguların takip süresi ortalama 11,8 ay olarak belirlendi (3-24 ay).

Tablo 3: Hasta ASA skorlamaları

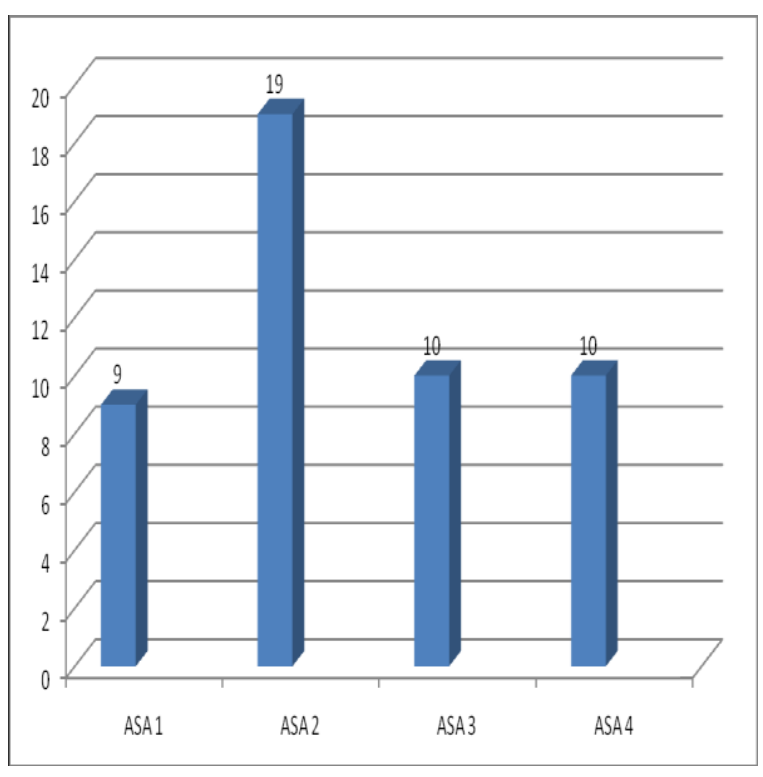

Hastalarin operasyon sirasinda ve post op dönemde drenden gelen kanama miktarlarının ortalaması 260,4 cc olarak bulundu. MIPO uygulanan 6 hastanın kanama miktarlarının ortalaması 175,3 cc olarak hesapland1. 14 (\%29) hastamıda post op kan transfüzyonu ihtiyac1 oldu. Ortalama kan transfüzyonu miktarı 1,8 üniteydi.

48 hastanın 1 'inde derin ve 2 'sinde yüzeyel olmak üzere $3(\% 6)$ hastada enfeksiyon gelişti.

Pertrokanterik kırık nedeniyle ameliyat edilen toplam 48 hastanın 43'ünde (\%89) kaynama sağlandı. Bu 43 hastanın 5 inde $(\% 11)$ varusda kaynama görüldü. Komplikasyonsuz olarak kaynama görülen hasta sayısı 38 di (\%79). Pertrokanterik kırık nedeniyle opere ettiğimiz hastaların ortalama kaynama süresi 17,6 hafta olarak belirlendi. MIPO 
yaptığımız 6 hastanın ortalama kaynama süresi 15,4 haftaydi.

Pertrokanterik kırık nedeniyle opere ettiğimiz 48 hastanın 5'ine psodoartroz nedeniyle reoperasyon uyguland $1 \% 11)$. Reoperasyon uygulanan hastaların 3'ü subtorkanterik kırık 2'si de intertrokanterik kırık olan hastalardı.

Subtrokanterik kırık olup psodoartroz tanis1 alan 3 hastadan 2'sine implant değiştirilmeden psodoartroz cerrahisi ve iliak otojen greft uyguland 1 bu hastaların takiplerinde operasyon sonras1 ortalama 4. ayda komplikasyonsuz tam kaynama görüldü. Subtrokanterik kırık olup psodoartroz tanısı alan diğer hastada 6. Ay kontrolünde medial korteks devamlılığında bozulma görülmesi nedeniyle implant çıkarımı+iliak otojen greftleme+Proksimal femoral çivileme yöntemiyle rekonstriksiyon yapıldı. Hastanın takiplerinde klinik ve radyolojik olarak sorun görülmedi.

İntertrokanterik k1rik olup psodoartroz tanisi alan hastalardan 1 hastaya ameliyat sonrasi 8 . Ayda implant çıkarımı ve total kalça protezi uygulandı. Diğer hastaya ise takiplerinin 7. Ayında derin doku enfeksiyonu görülesi üzerinde, implant çıkarımı+debritman ve eksternal fiksatör uygulaması yapıldı.
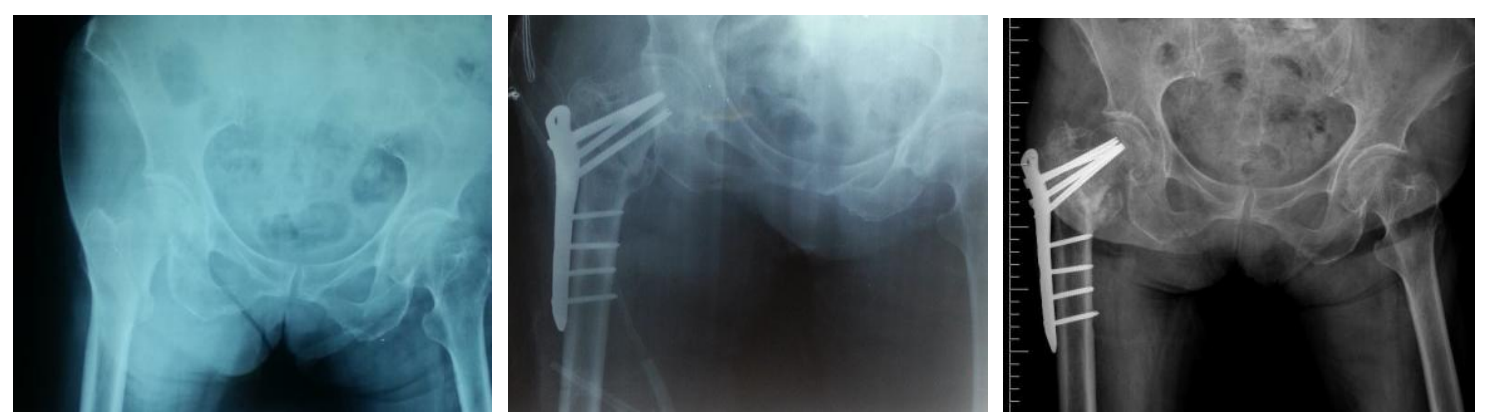

Resim 1. Sağ femur intertrokanterik kırık preoperatif grafi Resim 2. Sağ femur intertrokanterik kırık postoperatif 1. gün grafisi Resim3. Sağ femur intertrokanterik kırık postoperatif 4. ay grafisi

\section{Tartışma ve Sonuç}

$\mathrm{Bu}$ çalışmamızda femur pertrokanterik kırığ1 olan ve proksimal femoral kilitli kompresyon plağı ile tedavi ettiğimiz 48 hastanın erken dönem sonuçlarını inceledik. İntertrokanterik kalça kırıklarında kadın-erkek oranının değişik düzeylerde olmak ile birlikte kadın predominansinin korunduğu gözlenmektedir(6,7,8). Bizim çalışmamızda hastaların kadın-erkek dağılımı litaretürden farklı olarak erkeklerde \%48 kadınlarda \%42 olarak belirlenmiştir. $\mathrm{Bu}$ farkın sebebinin; hasta yaş ortalamasının literatüre göre daha düşük olması ve hastalarımız arasında yüksekten düşme ve trafik kazasına bağlı ameliyat edilen erkek hastaların sayısının fazla olmasına bağlı olduğunu düşünmekteyiz.

Ganz ve ark. 1376 olguluk serilerinde hastaların \%70'inde ev kazası, $\% 10$ 'ununda trafik kazası, \%9'unda iş kazası ya da spor yaralanması, \%11'inin ise nedeninin belirlenemediğini bildirmişlerdir (9). Bizim çalışmamızda 48 hastanın kırık oluş nedenleri; 9 olguda yüksekten düşme, 7 olguda trafik kazası, 32 olguda evde düşme sonucu olduğu belirlenmiştir.

Clawson ve Melcher, femur üst uç kırıklarının nedeni olarak ilk sırayı basit düşmelerin, ikinci sırayı trafik kazalarının aldığını belirtmişlerdir (10). 
Kalça kırı̆̆ı olan hastalarda ameliyat sonrası ölüm oranları ile ilgili birçok farklı sonuç bildirilmiştir. Yapılan çalışmalarda görüldüğü üzere en sık mortalite ilk 3 ay içerisinde olmaktadır (11). Kalça kırığı bulunan 406 hastalık bir çalışmada Kenzora yıllık mortalite oranını \%14 olarak vermiştir (12). 1966'da Horowitz ve arkadaşları mortalite oranının konservatif tedavi ile \%34,6 cerrahi tedavi ile \%17,5 olduğunu bildirmişlerdir. Ege ve arkadaşlarının yaptıkları bir çalışmada konservatif tedavi ile \%34 olan mortalite oranının cerrahi tedavi ile \%14'e indiği belirtilmiştir. Bizim çalışmamızda takiplerimiz boyunca sadece 1 hasta genel durum bozukluğu ve kardiyak problemlere bağlı kaybedilmiştir. Ölüm oranımızın düşük olmasını çalışmamızdaki hasta yaş ortalamasının literatürdeki hasta yaş ortalamasından daha genç olmasına bağladik.

Trokanterik bölge kırıkları kaynamaması \%1-2 oranındadır $(6,7,13)$. Bizim çalışmamızda kaynamama oranı $\% 11$ olarak belirlenmiștir. $\mathrm{Bu}$ hastaların 2'sinde gelişen enfeksiyon nedeni ile kaynamama gelişmiş olup, diğer iki olguda ileri derecede varus malpozisyonu, bir olguda ise kırı posteromedial bölgesindeki kemik defekti nedeni ile kaynamama ile karşılaşıldı.

Azboy ve arkdaşlarının yaptığ çalışmada proksimal femoral kilitli kompresyon plağı ile tedavi edilen hastaların ortalama kaynama süresi 17 hafta, açıl plakla tedavi edilen hastaların ortalama kaynama süresi 18 hafta olarak bulunmuştur (13).

Bizim çalışmamıza dahil edilen hastalarımızın ortalama kaynama süresi 17,6 hafta olarak olup, literatürle uyumlu olarak bulunmuştur. Çalışmamızda 5 hastada kaynamama ve 2 hastamızda kısalık tespit edildi. Varus gelişen 5 hastanın grafilerinde proksimal vidaların migre olduğu görüldü. $\mathrm{Bu}$ hastaların postoperatif grafileri incelendiğinde, 2 hastada kırığ intraoperatif stabil redüksiyonun tam olarak gerçekleşmediği saptand1. Diğer 3 hastada ise takiplerinde çekilen grafilerinde proksimal $6,5 \mathrm{~mm}$ lik kilitli vidaların plağın tespitinde kilitlenmenin yetersiz olarak yapılması nedeniyle migre olduğu düşünüldü.

Çalışmamızda minimal invaziv plak osteosentezi (MiPO) yaptığımız 6 hastanın hiçbirinde kaynamama veya başka bir komplikasyon görülmedi. MIPO yapılan 6 hastadaki ortalama kaynama süresi 15,4 hafta ve bu hastalardaki ortalama kanama miktarı ortalama 173,4 cc olarak belirlendi. MIPO yapılan hastalarımızdaki kanama miktarı litaratürden daha düşük bulundu.

Çalışmamızda 5 hastada varus malpozisyonu görülürken (\%11), hiçbir hastamıda vida siyrılması veya cut out görülmedi.

Hiçbir hastamızda implant kırı̆̆ görülmedi. 48 hastanın 5 'inde kaynamama ve 2 si yüzeyel, 1 'i derin olmak üzere toplam 3 hastamızda enfeksiyon görüldü.

Literatürde tekrar operasyon oranları incelendiğinde İMHS (İntramedüller hip screw) yapılan hastalarda \%3, kayıcı vida plak uygulamalarında $\% 6$, PFN'de ise $\% 4$ 12 oranında olduğu bildirilmiştir (14). Bizim çalışmamızda reoperasyon oranı $\% 11$ olarak belirlenmiştir.

Saarenpaa ve arkadaşlarının yaptığı bir çalışmada intramedüller implant (Gama nail, PFN, PFNA) uygulanan hastalarda $\% 8,2$ oranında reoperasyon oran1 bildirilmiştir (15). Yine uzun ve arkadaşlarının intramedüller implantlara yaptığı çalışmada non union oranı $\% 5.7$, sekonder varus malpozisyonu oranı $\% 25.7$ ve reoperasyon oran1 \%14.7 olarak belirtilmiştir (16). Bizim çalışmamızda reoperason oran $1 \% 11$ olarak belirlenmiştir. Sonuç olarak; pertrokanterik femur kırıklarının tedavisinde iyi bir kırık redüksiyonu sonrası kaliteli bir fiksasyonun şart olduğu,bu çalışmada kullanilan proksimal femoral kilitli kompresyon plağının MiPO uygulamasına olanak vermesi özelliği ile hastaların postoperatif morbiditelerinin daha düşük 
olacağı ve kaynama süresinin klasik açık yönteme göre daha kısa sürede olacağı kanılarına varılmıştır.

\section{Çıkar Çatışması: Yok}

\section{Kaynaklar}

1. Lavelle DG. Fractures and dislocations of the Hip. In: Canale ST, Beaty JH Campell's Operative Orthopaedics. Mosby Year Book, Philadelphia 2008, pp 3237-3285

2. Kyle RF, Campbell SJ. Intertrochanteric Fractures. In: Chapman MW (ed), Operative Orthopaedics (2. Ed) J.B. Lippincott Company, Philadelphia 1993, pp 595604

3. Levy RN, Capozzi JD, Mont MA. Intertrochanteric Hip Fractures.In: Browner DB, Jupiter JB, Levine AM. (eds) Skeletal Trauma V:2; WB Saunders Company, USA 1992, pp 1443-1471

4. DeLee JC. Fractures and Dislocations of the Hip, Rockwood and Green's Fractures in Adults Vol.2; Lippincott-Raven,1996: 1659-1827

5. Green S, Moore T. Bipolar prosthetic replacement for the management of unstable inter trochanteric hip fractures in the elderly. Clin Orthop. 1987;224:168177

6. Browner DB, Jüpiter JB, Levine AM, Trafton PG. Skeletal Trauma V:2; WB Saunders Company, 1996: 1833-1926

7. DeLee,J.C.: Fractures and dislocations of the hip. Rockwoods and Green's fractures in adults:14811555, J.B.Lippincott Company,3rd.,Phil.,1996
8. Ege, Rıdvan: Kalça Cerrahisi ve Sorunları; Türk Hava Kurumu Basımevi Ankara, 1994

9. Ganz R, Thomas RJ, Hammerle CP. Trochanteric fractures of the femur. Treatment and results. Clin Orthop. 1979; 138:230

10. Koval K, Zuckerman J. İntertrochanteric Fractures. Rockwood and Green's Fractures in Adults. Philedelphia 2001; Vol 2: 1635-1663

11. Davidson T.I.;Bodey, W.N.Facros influencing survival following fractures of the upper end of the femur. Injury 17:12-14,1986

12. Kenzora JE, McCarty RE, Lowell RD. Hip fracture mortality: relation to age, treatment, preoperative illness, time of surgery and complications. Clin Orthop. 1984;186:45-51

13. I.Azboy MD, A.Demirtaş MD, M.Gem MD a compression of proximal femoral locking plate versus 95 degree angaled blade plate in the treatment of reverse intertrokanterik fractures. Eklem Hastalik Cerrahisi. 2014;25(1):15-20

14. Loch DA, Kyle RF, Bechtold JE, Kane M, Anderson $\mathrm{K}$, Sherman RE: Forces required to initate sliding in second generation intramedullary nails. J Bone Joint Surg B0-A (11) t 7626 - 31, 1998

15. Cummings SR, Rubin SM, Black D. The Future of Hip Fractures in United States: Costs and Potential Effects of Postmenopausal Estrogen. Clin Orthop 1990; 252:163-166

16. Baumgaertner $M$, Thomas $H$. Femoral Neck Fractures, Rockwood and Green's Fracrures in Adults. Philedelphia 2001; Vol 2:1579-1634 